\title{
Surface anchored metal-organic frameworks as stimulus responsive antifouling coatings
}

\author{
Maria Pilar Arpa Sancet ${ }^{1,2+}$, Maximilian Hanke ${ }^{1,2,3 \dagger}$, Zhengbang Wang ${ }^{1}$, Stella Bauer ${ }^{1,2}$, Carlos Azucena ${ }^{1}$, \\ Hasan K Arslan ${ }^{1}$, Marita Heinle ${ }^{1}$, Hartmut Gliemann ${ }^{1}$, Christof Wöll ${ }^{1 *}$ and Axel Rosenhahn ${ }^{1,4^{*}}$
}

\begin{abstract}
Surface-anchored, crystalline and oriented metal organic frameworks (SURMOFs) have huge potential for biological applications due to their well-defined and highly-porous structure. In this work we describe a MOF-based, fully autonomous system, which combines sensing, a specific response, and the release of an antimicrobial agent. The Cu-containing SURMOF, Cu-SURMOF 2, is stable in artificial seawater and shows stimulus-responsive anti-fouling properties against marine bacteria. When Cobetia marina adheres on the SURMOF, the framework's response is lethal to the adhering microorganism. A thorough analysis reveals that this response is induced by agents secreted from the microbes after adhesion to the substrate, and includes a release of $\mathrm{Cu}$ ions resulting from a degradation of the SURMOF. The stimulus-responsive antifouling effect of CU-SURMOF 2 demonstrates the first application of CU-SURMOF 2 as autonomous system with great potential for further microbiological and cell culture applications.
\end{abstract}

Keywords: Metal-organic frameworks; MOF; Cobetia marina; Marine bacteria; Biofouling; Stimulus responsive; Smart surface; Cu; Biocide

\section{Background}

Biocide release into the environment is subject to an increasingly strong regulation. For the formulation of marine antifouling coatings, organo-tin compounds have already been banned and the use of copper-based paints on hulls of recreational vessels in certain areas of Europe has recently been restricted [1-3]. However, control of biofouling-the unwanted colonization of submerged surfaces by biological substances and organisms-is of major environmental and socioeconomic relevance as it affects many marine industries. Especially in shipping industry heavy fouling results in higher fuel consumption with major environmental and economic penalties [3-5]. Copper-based coatings and paints are frequently used to control biofouling on ship hulls and are currently the workhorse of the coatings industry [5,6]. The release of copper from these protective coatings into the environment is substantial and reaches 1000 tons per year for a

\footnotetext{
* Correspondence: christof.woell@kit.edu;

axel.rosenhahn@rub.de

†'Equal contributors

'Institute of Functional Interfaces (IFG), Karlsruhe Institute of Technology,

PO Box 3640, 76021 Karlsruhe, Germany

Full list of author information is available at the end of the article
}

large, 65,000 Gross Registered Ton container ship that is $260 \mathrm{~m}$ in length [6].

For the reduction of metal ions released into the environment urgently smart coatings are needed, which e.g. rely on stimulus-responsive chemistries. Ideally, such coatings would combine a dormant state, the sensing for the presence of microbes, a switching to an active state and finally the release of a biocide. A combination of these different functions into a coating represents a major challenge. Metal organic frameworks (MOFs), also referred to as porous coordination polymers (PCPs), consist of metal or metal-oxo connectors and organic linkers and have been used in a variety of applications such as the storage of molecules or drug delivery $[7,8]$. In this article, we demonstrate that a particular class of surface-anchored metal-organic frameworks (SURMOFs) based on $\mathrm{Cu}^{2+}$, called $\mathrm{Cu}-\mathrm{SURMOF} 2$, show the required autonomous actions by exploiting their properties as a stimulus-responsive anti-fouling material.

\section{Methods}

Preparation of gold substrates

Gold substrates were purchased by PVD Beschichtungen (Silz, Germany). Thin films of polycrystalline gold were prepared by thermal vapour deposition of $30 \mathrm{~nm}$ gold 
(99.99\% purity) onto Nexterion ${ }^{\circledR}$ B glass slides (Schott, Mainz, Germany) predeposited with a $5 \mathrm{~nm}$ titanium adhesion layer. Evaporation was performed at a pressure of $2 \times 10^{-7}$ mbar and a deposition rate of $0.5 \mathrm{~nm} \mathrm{~s}^{-1}$, leading to a root-mean-square (rms) roughness of about $1 \mathrm{~nm}$. Gold substrates were stored under argon until used.

\section{SAM preparation}

In order to synthesize 16-mercaptohexadecanoic acid (MHDA) or hexadecanthiole (HDT) SAMs, a thiol solution was prepared as described in previous studies by dissolving the respective thiole solution (90\%, Aldrich, purified by recrystallizing twice before use) in a $5 \%$ volume mixture of acetic acid in ethanol to reach the desired concentration of $20 \mu \mathrm{M}$. A clean gold substrate was placed in this solution for $48 \mathrm{~h}$ and then rinsed with the pure solvent and gently dried under nitrogen flux.

\section{SURMOF preparation}

SURMOFs 2 were prepared by employing the spray method [9] which has been successfully used in other layerby-layer fabrication schemes for coating substrates e.g. polyelectrolyte multilayers. SURMOF 2 layers were grown on MHDA SAMs. These substrates were placed on a sample holder and subsequently sprayed with a $1 \mathrm{mM}$ ethanol solution of $\mathrm{M}_{2}\left(\mathrm{CH}_{3} \mathrm{COO}\right)_{4} \cdot \mathrm{H}_{2} \mathrm{O}, \mathrm{M}=\mathrm{Cu}$ or $\mathrm{Zn}$ ) for $10 \mathrm{~s}$ and then with a $0.2 \mathrm{mM}$ 1,4-benzendicarboxylic acid (CBD) solution for $20 \mathrm{~s}$ at room temperature. Between each step, the substrates were rinsed with ethanol. Critical parameters of the spray procedure were carrier gas pressure (1.5 bar), liquid pressure $(0.2 \mathrm{bar})$, flow rate $(0.25 \mathrm{ml} / \mathrm{s})$, and distance between the nozzle and the target $(0.1 \mathrm{~m})$. The number of deposited layer varies depending on the desired thickness of the SURMOFs 2. For this work, three kinds of $\mathrm{Cu}$ SURMOFs 2 were prepared. For the synthesis 15 layers were required resulting in a $\sim 120 \mathrm{~nm}$ thickness. This kind of SURMOF 2 was the one most commonly used in this work. To prepare SURMOFs with $\sim 80 \mathrm{~nm}$ thickness, 10 layers were applied while 20 layers resulted at a thickness of $\sim 160 \mathrm{~nm}$.

\section{SURMOF stability assays}

The stability of $\mathrm{Cu}-\mathrm{SURMOF} 2$ in different aqueous media was investigated. The media used were Milli-Q ${ }^{\circ}$ water, artificial seawater (ASW, Instant Ocean ${ }^{\circledR}$ ), PBS buffer, PBS buffered fibrinogen solution $(1 \mathrm{mg} / \mathrm{ml})$ and Dulbecco's Modified Eagle cell culture medium (DMEM; $10 \%$ fetal cord serum, 5\% L-Glutamine, 5\% Penicillin/ Streptomycin). The samples were incubated in the different media for $1 \mathrm{~h}$ on a vibrational table $(60 \mathrm{rpm})$ at room temperature. After incubation, the solutions were diluted with 11 distilled water and the samples were removed from the solution and carefully rinsed with Milli-
$\mathrm{Q}^{\bullet}$ water before being characterized by X-ray diffraction (XRD) and X-ray photoelectron spectroscopy (XPS).

\section{X-ray diffraction (XRD)}

For all SURMOF 2 samples, out-of-plane XRD $\theta-2 \theta$ scans were recorded after synthesis and after the immersion into different solutions. XRD measurements of SURMOFs 2 were performed using a Bruker D8Advance diffractometer with $\theta-2 \theta$ geometry and $\mathrm{Cu} \mathrm{K}$ radiation $(\lambda=1.54 \AA)$ as $\mathrm{X}$-ray source. Measurements were recorded by a PSD detector (MBraun, Garching, Germany) by a copper $K_{\alpha}$ radiation at $40 \mathrm{kV} / 30 \mathrm{~mA}$, with a step size of $0.007^{\circ}$ and scan time of $3 \mathrm{~s}$ in the range of $2 \theta=5^{\circ}-30^{\circ}$.

\section{X-ray photoelectron spectroscopy (XPS)}

The surfaces were analyzed by X-ray photoelectron spectroscopy (XPS) using a Leybold-Heraeus MAX 200 Xray photoelectron spectrometer with a magnesium anode as X-ray source $\left(\mathrm{K}_{\alpha}=1253,6 \mathrm{eV}\right)$. Peak fitting was performed with the software XPSPeak 4.1 (Prof. R. W. M. Kwok, Department of Chemistry, University of Hong Kong) after using a Shirley background substraction.

\section{Bacterial culture}

Cobetia marina [10] (DSM 4741) was obtained as dried culture from DSMZ ("Deutsche Sammlung von Mikroorganismen und Zellkulturen" GmbH, German Collection of Microorganisms and Cell Cultures, Braunschweig, Germany). Marine Broth (MB) and ASW were prepared according to the manufacturer's instructions. Culture and bacterial assays followed recently published protocols [11]. For bacterial assays, a single colony from an agar plate was inoculated into $20 \mathrm{ml} \mathrm{MB}$ overnight while shaking on a vibrational table $(65 \mathrm{rpm})$ at room temperature. The overnight culture was diluted 1:100 in sterile $\mathrm{MB}$ and held in liquid culture until the desired $\mathrm{OD}_{600}$ of 0.1 (log-phase) was reached. This suspension was centrifuged at 10,000 rpm for $2 \mathrm{~min}$. The bacterial pellet was resuspended in sterile ASW and used for the experiments instantly. The number of bacteria in the suspension with an $\mathrm{OD}_{600}$ of 0.1 was in order of $10^{7}$ cells $\mathrm{ml}^{-1}$ approximately. For the preparation of the EPS solution from $C$. marina the ASW bacterial solution was first incubated in an Erlenmeyer flask for $2 \mathrm{~h}$. Subsequently the EPS from the solution was separated from the bacteria following published protocols [12].

\section{Bacterial viability assays}

The live/dead ${ }^{\ominus}$ BacLight $^{\text {TM }}$ bacterial viability kit (Invitrogen, Carlsbad, CA, USA) was used to determine the viability of the bacteria after $2 \mathrm{~h}$ incubation on $\mathrm{Cu}$ SURMOF $2(\sim 120 \mathrm{~nm}$ thickness $)$ and MHDA SAM as non-toxic control. This viability assay was often used in 
other previous studies $[13,14]$. The assay which was performed following the manufacturer's experimental protocol uses a mixture of Syto 9 green-fluorescent nucleic acid stain and the red-fluorescent nucleic acid stain propidium iodide. These stains differ both in their ability to penetrate healthy bacteria and in their emission wavelength. While the Syto 9 stain labels all bacteria, the propidium iodide only penetrates bacteria with damage membranes, as cells with intact membranes are impermeable to this dye. Thus, this assay is well suited for a viability bacterial analysis using fluorescence microscopy as recommended from the manufacturers. Prior to staining, the surfaces were incubated for 2 hours in a bacterial suspension in $\mathrm{ASW}$ at an optical density $\mathrm{OD}_{600}=0.1$. Subsequently, $3 \mu$ l of 1:1 mixture of both stains (redand green-fluorescent nucleic stain) was added for each $\mathrm{mL}$ of bacterial solution and incubated at room temperature in the dark for 15 minutes. The samples were removed from the solution, and rinsed with Milli$\mathrm{Q}^{\circ}$ water. All samples were analyzed by florescence microscopy with an upright Nikon microscope $90-\mathrm{i}$ and suitable optical filters (BV-2A and Texas red HYQ, Nikon, Tokyo, Japan) using a $40 \times$ objective. The ratio between dead and living bacteria was determined by evaluation of the number of fluorescing bacteria in the microscopy images.

\section{Microfluidic bacterial detachment assay}

The adhesion strength of the bacterium Cobetia marina on SURMOF 2 was quantified using a custom built microfluidic setup [15] which has previously been utilized to study cell and bacterial [11] adhesion on surfaces. The channels (dimensions: $13 \mathrm{~mm} \times 1 \mathrm{~mm} \times$ $140 \mu \mathrm{m}$ ) were positioned between a glass lid and the coated surface to be investigated. Four fully assembled channel systems containing four surfaces with different coatings were mounted on the stage of an inverted microscope (Nikon TE-2000) allowing a simultaneous incubation of the samples. Bacteria suspensions with an $\mathrm{OD}_{600}=0.1$ were injected into all four channels and incubated for $2 \mathrm{~h}$ as established in previous protocols [11]. After the incubation phase, medium from a reservoir was aspirated through the channels by a computer controlled syringe pump generating a flow which was increased stepwise by $26 \%$ every $5 \mathrm{~s}$. The detachment was followed via video microscopy with a $40 \times \mathrm{Ph} 2$ objective and the fraction of adherent bacteria was determined every $5 \mathrm{~s}$. The removal from all four channels was done sequentially. The wall shear stress $\tau$ created by the liquid flow was calculated by Poiseuille's model under a Purday approximation [15-17]. From the removal curves (decreasing number of bacteria over time), the critical shear stress needed to detach $50 \%$ of the adherent bacteria $\left(\tau_{50}\right)$ as measure of how strongly the bacteria attached to the surfaces, was obtained. Each measurement was repeated at least four times. The $\tau_{50}$ values are the mean of all measurements, error bars are the standard error of the mean (SEM).

\section{Atomic force microscope (AFM)}

After $2 \mathrm{~h}$ incubation, the bacteria were air dried overnight following published protocols [18,19]. Bacteria were imaged using an Asylum Research Atomic Force Microscope, MFP-3D BIO. The AFM was operated at $25^{\circ} \mathrm{C}$ in an isolated chamber in alternating current mode (AC mode). AFM cantilevers were purchased from Ultrasharp $^{\text {tm }}$ MikroMasch. Three types of AFMcantilevers were used, an NSC-35 (resonance frequency $315 \mathrm{kHz}$; spring constant $14 \mathrm{~N} / \mathrm{m}$ ), an NSC-36 (resonance frequency: $105 \mathrm{KHz}$; spring constant: $0.95 \mathrm{~N} / \mathrm{m}$ ) and an NSC-18 (resonance frequency: $75 \mathrm{kHz}$; spring constant: $3.5 \mathrm{~N} / \mathrm{m}$ ).

\section{SEM measurements}

For the characterization of the samples by SEM, the bacteria were fixed by immersion into ice cold methanol for $3 \mathrm{~min}$. Finally the samples were air dried. These SEM images were obtained on a FEI Philips XL 30 Field Emission Gun Environmental Scanning Electron Microscope (FEG-ESEM), operated in SEM-Mode at an acceleration voltage of $15 \mathrm{kV}$ under a chamber pressure of $100 \mathrm{~Pa}$ and under High Vacuum $\left(10^{-5} \mathrm{~Pa}\right)$. For the evaluation of the morphological changes of $\mathrm{C}$. marina after incubation on $\mathrm{Cu}$-SURMOF 2, the bacteria were air dried without previous fixation. Prior to SEM measurements, the samples were sputtered in a Baltec MED 020 sputter coater with a $5 \mathrm{~nm}$ thick conductive layer of $\mathrm{Au} / \mathrm{Pd}(80 / 20)$.

\section{ICP-OES measurements}

Copper concentrations were measured by inductively coupled plasma optical emission spectrometry (ICPOES; OPTIMA 8300DV, Perkin-Elmer). The sample flow was set to $1 \mathrm{ml} / \mathrm{min}$. The HF-generator operated at $1400 \mathrm{~W}$. Gas flows were $15 \mathrm{l} / \mathrm{min}$ for the plasma, $0.5 \mathrm{l} /$ min for the thrust gas and $0.55 \mathrm{l} / \mathrm{min}$ for the vaporizer gas. The copper bands analyzed were the signals at $327.393 \mathrm{~nm}$ and at $324.752 \mathrm{~nm}$.

\section{Results}

Stability of the Cu-SURMOF 2 in aqueous media and bacteria suspensions

The stability of $\mathrm{Cu}$-SURMOF 2 (120 nm thickness) in various media was analyzed by XPS and XRD. Figure 1 shows virtually the same XP spectra of the $C 1$ s (A) and the $\mathrm{Cu} 2 \mathrm{p}(\mathrm{B})$ peak for the pristine surfaces and after a $2 \mathrm{~h}$ incubation in Milli- $\mathrm{Q}^{\circ}$ water. After an equally long incubation in artificial seawater (ASW, Instant Ocean ${ }^{\circ}$ ), only minor peak changes became visible as the $\mathrm{Cu} 2 \mathrm{p}$ 


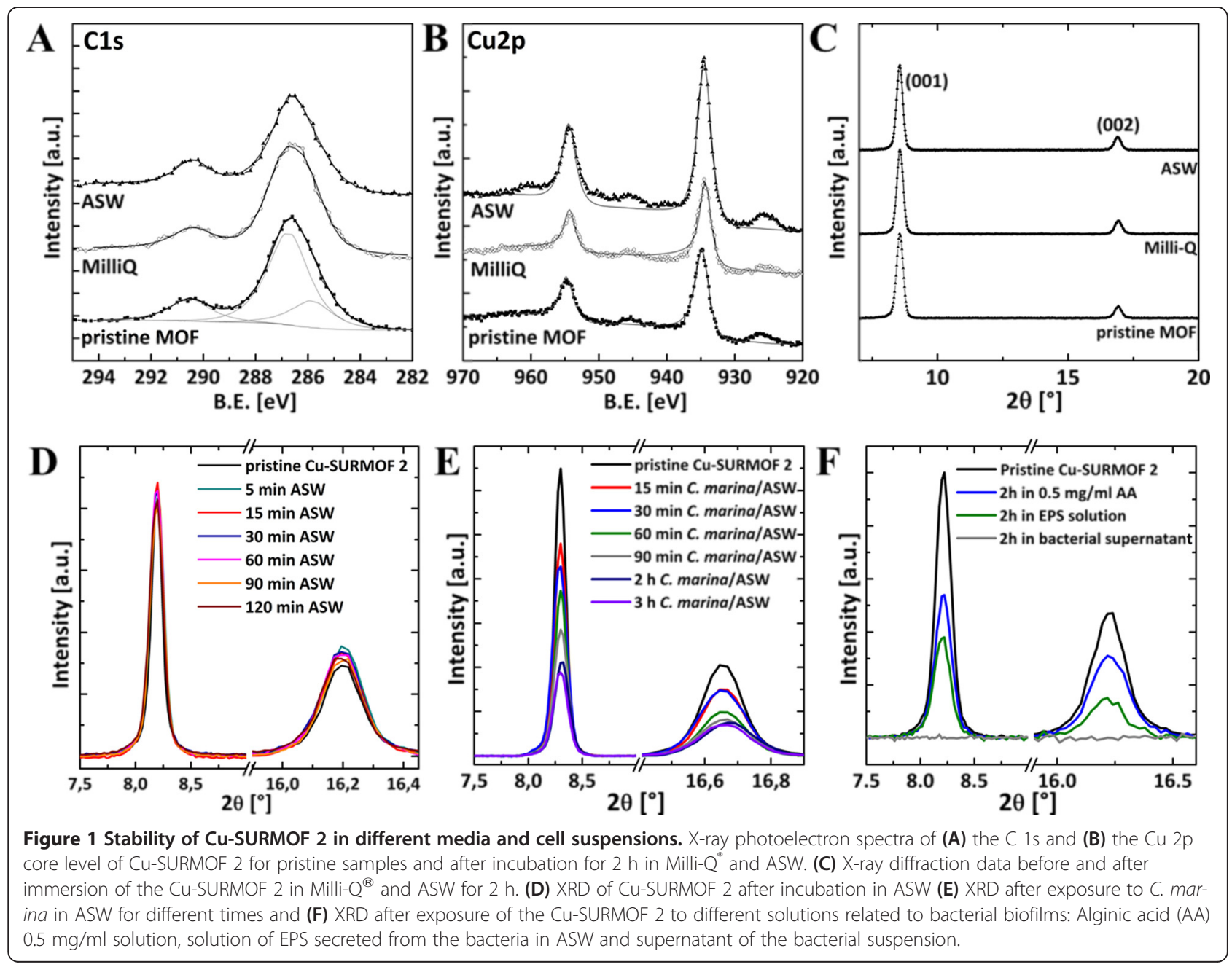

peak slightly increased, while the $\mathrm{C} 1 \mathrm{~s}$ peak showed a marginal reduction. In agreement with previous data, [20] this indicates a disassembly of the top layers of the SURMOF structure resulting in better spectroscopic accessibility of the $\mathrm{Cu}^{2+}$ dimers and a loss of some benzene-1,4-dicarboxylate (bdc) linkers. XRD measurements prove that all samples retained their crystallinity (Figure 1C, 1D).

The bacterium used in this work was Cobetia marina, a model marine bacterium used in adhesion studies due to its relevance in marine biofouling $[11,21,22]$. As bacteria cause an additional XPS signal, only XRD was applicable for detecting changes in the SURMOF. Incubation of $\mathrm{Cu}$-SURMOF 2 with C. marina in ASW led to significant reduction of the XRD signal intensity over the course of $2 \mathrm{~h}$ (Figure 1E). In the process of attaching to a surface the bacteria secrete EPS composed of macromolecules, which are mostly polysaccharides [23] such as alginic acid (AA) [24]. That such biomolecules can affect the metalorganic frameworks is demonstrated by incubation of test samples in different solutions related to the bacterial physiology (Figure 1F).

A $2 \mathrm{~h}$ incubation in both, AA solution and a solution of EPS led to a dramatic decrease in the XRD peak intensities. After immersion into the supernatant of a bacterial suspension, a complete loss of crystalline order was observed. Inductively coupled plasma optical emission spectrometry (ICP-OES) measurements of the test solutions revealed significantly increased copper concentrations (Additional file 1: Figure S1). The highest copper concentrations of $\sim 2 \mathrm{mg} / \mathrm{l}$ were measured after $2 \mathrm{~h}$ exposure of the $\mathrm{Cu}$-SURMOF 2 to the supernatant of bacterial suspensions and after incubation in suspensions of C. marina.

Atomic force microscopy (AFM) and scanning electron microscopy (SEM) were performed to determine the localization of the microbe-induced $\mathrm{Cu}$-SURMOF 2 degradation (Additional file 2: Figure S2 and Additional file 3: Figure S3). SEM images show that bacteria removed during the preparation for electron microscopy left behind a dark spot at the position of their original 
attachment. Tilted images reveal that the SURMOF next to the bacterium remains unaffected. A thickness of $\approx 160 \mathrm{~nm}$ after bacterial incubation as determined by AFM is the typical thickness of a Cu-SURMOF 2 consisting of 20 layers, supporting the notion that degradation is highly localized.

\section{Adhesion, viability, and morphology of marine bacteria Cobetia marina on Cu-SURMOF 2}

Bacterial viability was determined by a live/dead assay on the Cu-SURMOF 2 (15 layers) and MHDA SAM as a non-copper containing control, after $2 \mathrm{~h}$ immersion in bacterial ASW solution. The green fluorescent nucleic acid stain labeled all bacteria while only bacteria with damaged membranes were labeled by red fluorescent dye. The fluorescence microscopy images (Figure 2A, 2B) after $2 \mathrm{~h}$ incubation of the bacteria on MHDA and $\mathrm{Cu}$-SURMOF 2 show a large number of damaged bacteria, especially on the Cu-SURMOF 2. The ratio of damaged versus all bacteria was determined by evaluating the fluorescence signal (stained areas) in the microscopy images. A majority of the bacterial population was stained red on the Cu-SURMOF 2 (88\%). In contrast, this fraction was only $0.9 \%$ on the MHDA SAM.

In addition to the viability studies we applied a microfluidic adhesion strength assay to investigate the influence of the active degradation of the Cu-SURMOF 2 on the adhesion of $\mathrm{C}$. marina (Figure 2C). Microfluidic detachment assays were performed on Cu-SURMOF 2 (15 layers and 10 layers, respectively) and on hexadecanethiol (HDT) and mercaptohexadecanoid acid (MHDA) self-assembled monolayers (SAMs) as copper-free controls. Additionally, two types of surfaces with known low adhesion strength were included, polyethylene glycol (PEG) [11] and hyaluronic acid (HA) [25]. Both surfaces are known for their protein and cell resistance; thus, they provide a suitable control as typical inert surfaces.
As shown in Figure $2 \mathrm{C}$, the shear stress needed to detach the bacteria (t50) is significantly lower for both $\mathrm{Cu}$ SURMOF 2 coatings of differing thicknesses compared to the HDT and MHDA SAM controls. Even though the trend is similar within the error bars, the $120 \mathrm{~nm}$ thick $\mathrm{Cu}$-SURMOF 2 reduced adhesion more effectively than the $80 \mathrm{~nm}$ thick sample. An ANOVA test was performed between the critical shear stress $\tau 50$ values showing a high significance of the data (at a 0.01 level). A post-hoc Tukey test reveals that the HA coatings, PEG SAMs, and both $\mathrm{Cu}$-SURMOF 2 coatings showed a statistically significant difference compared to the MHDA and HDT SAMs. These results demonstrate that Cu-SURMOF 2 led to a significant reduction of adhesion strength to a degree comparable to established protein and biofouling resistant surfaces.

A $3 \mathrm{D}$ visualization of the AFM images shows that the bacteria have a wrinkled surface when incubated on $\mathrm{Cu}$ SURMOF 2 (Figure 3B). In contrast, bacteria incubated on HDT SAM had a normal, smooth morphology (Figure 3A) and the surface roughness of the bacteria was $\sim 50 \%$ lower than that on the Cu-SURMOF 2 (Figure 3C). Furthermore, the mean width of bacteria on the Cu-SURMOF 2 was $\sim 25 \%$ larger compared to that on HDT SAM (Figure 3D), supporting the visual impression that the bacteria are flatter and broader. These observations show that reduced adhesion and viability of the bacteria on Cu-SURMOF 2 is associated with obvious morphological changes.

\section{Discussion}

$\mathrm{Cu}$-SURMOF 2 is stable with regard to high-purity water and artificial seawater (ASW). Obviously, immersion into these liquids does not change $\mathrm{x}$-ray diffraction (XRD) peak intensities or their positions. After immersion in ASW for two hours, data from X-ray photoelectron spectroscopy (XPS) show a slight increase in the $\mathrm{Cu} 2 \mathrm{p}$ signal and a small
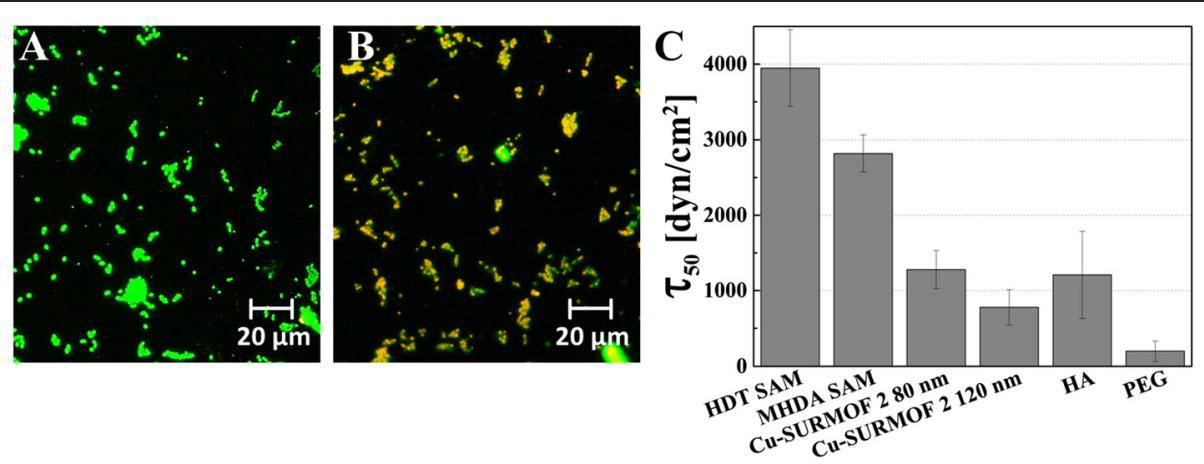

Figure 2 Viability and adhesion analysis of $C$. marina in contact with CU-SURMOF 2. Fluorescence microscopy images of adherent bacteria after BacLight ${ }^{\text {TM }}$ bacterial viability staining on (A) MHDA SAM and (B) Cu-SURMOF 2 (15 layers). (C) Critical shear stress ( $\left.\tau_{50}\right)$ required to remove the bacteria from CU-SURMOF 2 surfaces for different controls. Error bars indicate the standard error of six experiments in the case of Cu SURMOF 2 (10 layers) and HDT SAM, and four experiments for all other surfaces. 

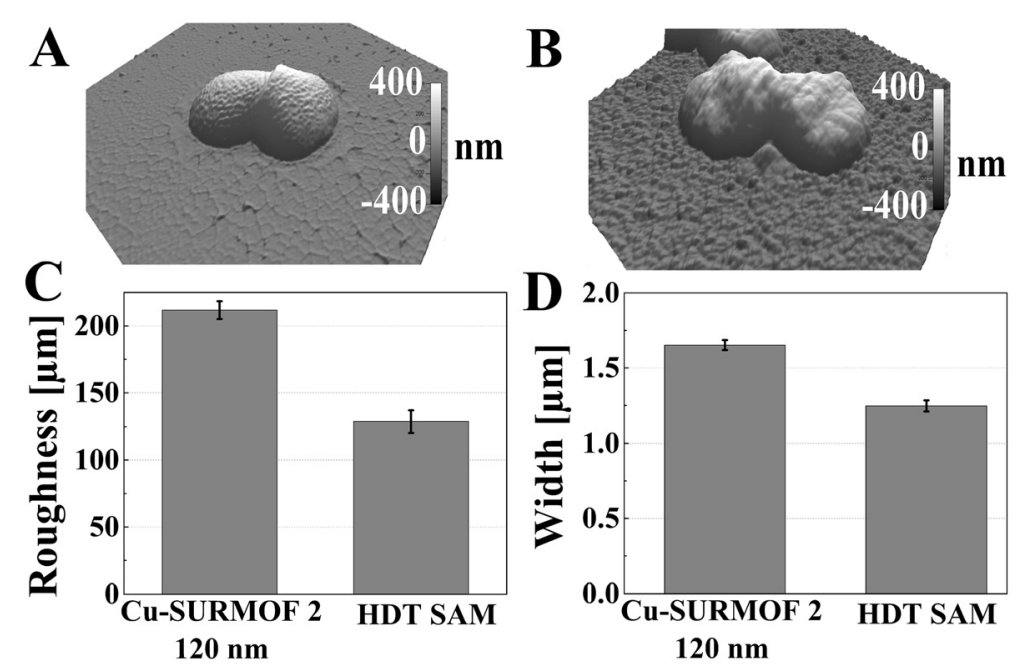

Figure 3 AMF analysis of the shape and morphology of $C$. marina in contact with Cu-SURMOF 2 in comparison to uninfluenced bacteria. AFM images of the bacteria on (A) HDT SAM and (B) Cu-SURMOF 2. (C) Mean roughness and (D) mean width of the bacteria. Measurements were obtained on seven individual bacteria. Error bars are the standard errors.

decrease in the $\mathrm{C} 1 \mathrm{~s}$ peak, indicating a small structural rearrangement in the near-surface region. However, dramatic changes are observed by adding Cobetia marina, a model marine bacterium frequently used for adhesion studies in the context of biofouling research, to the ASW. The XRD data reveal a dramatic decrease in the diffraction peak intensities. Since there is no substantial overall loss of material, this observation indicates a structural rearrangement brought about by the interaction of the bacteria with the MOF substrate. Scanning electron microscopy (SEM) and
AFM images (Additional file 3: Figure S3, Additional file 4: Figure S4 and Figure 4) show that the morphological changes are mainly localized in the vicinity of the adhering bacterium. The most likely explanation for these severe structural changes is the release of biomolecules by Cobetia marina. This hypothesis is supported by the fact that the investigated MOF materials, while stable in clean water and artificial seawater, react strongly to phosphate buffer or protein-rich media resulting in a structural rearrangement or decomposition, respectively. Since short peptides and
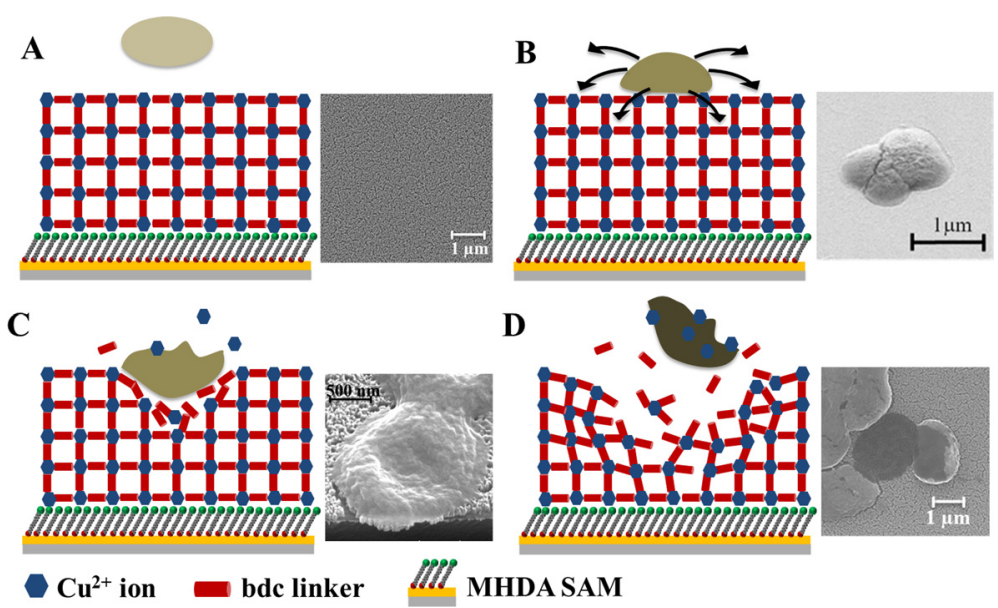

D

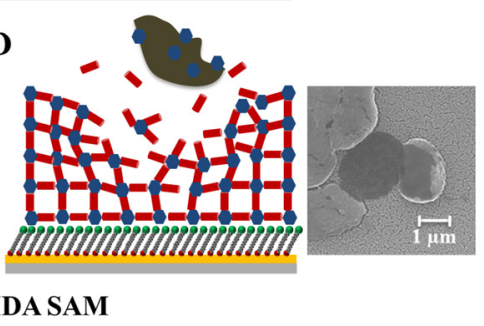

Figure 4 Schematic illustration of the active disassembly of the Cu-SURMOF 2 under the influence of $C$. marina. (A) Healthy bacteria in initial contact with the SURMOF. The SEM image shows a pristine CU-SURMOF 2 surface without the influence of C. marina. (B) Bacteria settled on the intact SURMOF begins secretion of EPS and other molecules. The SEM image shows a bacterium on a HDT SAM. HDT presents a surface on which the bacteria can grow unaffected. (C) Disassembly of the SURMOF and release of $\mathrm{Cu}^{2+}$ ions. The SEM image shows a bacterium on a Cu-SURMOF 2 surface after $2 \mathrm{~h}$ incubation on the substrate. The bacterium is clearly deformed. (D) Adverse effect on bacteria leading to reduced viability and adhesion strength. The SEM image shows a bacterium with adhesion weakened by the SURMOF 2 so that it detached during preparation for the SEM leaving behind a dark spot. 
small biomolecules are sufficiently small to fit within the SURMOF pores with a size of $1.1 \mathrm{~nm}$ [26], we propose that extracellular polymeric substances (EPS) and other macromolecules secreted by bacteria diffuse into the porous support. This leads to a structural rearrangement and partly destruction within the crystalline coordination polymer and subsequently a loss of crystalline order.

The most important observation is made by inspecting the fluorescence microscopy images, recorded after applying a live/dead assay. They demonstrate that the majority of bacteria are dead after a two-hour exposure to the $\mathrm{Cu}$ SURMOF 2 substrate. Control experiments conducted with the same substrates but without the SURMOF coating showed a high, normal viability of the microorganism. The most straightforward explanation of this surprising observation is that $\mathrm{Cu}^{2+}$ ions are released upon the Cobetia marina-induced structural rearrangement and local disassembly of the supporting MOF. Control experiments in which the SURMOFs are exposed to suspensions of C. marina, a solution of extracellular polymeric substance (EPS) secreted by C. marina, and supernatants of bacteria suspensions indeed reveal that there are small concentrations of $\mathrm{Cu}^{2+}$ in the corresponding solutions (Additional file 1: Figure S1). Similar experiments using SURMOFs where the $\mathrm{Cu}$ ions are replaced by $\mathrm{Zn}^{2+}$ ions [27] showed no particular effect on the bacteria.

On the basis of these observations we propose the scenario depicted in Figure 4. After attaching to the SURMOF substrate (which is stable in ASW), the bacteria release biomolecules which diffuse into the MOF and lead to a structural rearrangement of the MOF material. This structural arrangement is likely to include an exchange of ions, which in turn leads to a release of a small amount of $\mathrm{Cu}$ ions. These ions are toxic to microorganisms [28]. These results are supported by adhesion experiments that show a strong reduction in adhesion of Cobetia marina to SURFMOF-coated substrates, reaching the low levels typically observed for inert surfaces such as polyethylene glycol or hyaluronans $[11,25]$.

\section{Conclusion}

In summary, $\mathrm{Cu}$-SURMOF 2 represents a novel class of stimulus responsive coatings with built-in antifouling properties. The autonomous response of the Cu-SURMOF 2 is a fundamental concept, which will be exploited in novel antifouling coatings with strongly reduced release of copper into the environment. Beyond biofouling research, we expect that this innovative concept will be exploited in further microbiological and cell culture applications.

\section{Additional files}

Additional file 1: Figure S1. ICP-OES measurement of the copper release by Cobetia marina and its byproducts. After incubating the $\mathrm{Cu}-$ SURMOF 2 in different media connected with the physiology of the bacteria, the copper concentration in the solution was determined by inductively coupled plasma optical emission spectrometry (ICP-OES). The media used were the same ones as in the XRD analysis (Figure 1F of the main article). Pure ASW showed the lowest copper concentration $(0.555 \mathrm{mg} / \mathrm{l} \pm 0.005 \mathrm{mg} / \mathrm{l})$, which is in line with the slight decrease of the XRD signal intensity detected. The solutions after incubation with $C$. marina $(2.085 \mathrm{mg} / \mathrm{l} \pm 0.095 \mathrm{mg} / \mathrm{l})$ and with the bacterial supernatant ( $2.060 \mathrm{mg} / \mathrm{l} \pm 0.130 \mathrm{mg} / \mathrm{l}$ ) showed the highest copper concentration. This is in line with the disassembly of the CU-SURMOF 2 samples by these solutions. The EPS solution $(1.605 \mathrm{mg} / \mathrm{l} \pm 0.005 \mathrm{mg} / \mathrm{l})$ and the solution of alginate $(1.630 \mathrm{mg} / \mathrm{l} \pm 0.040 \mathrm{mg} / \mathrm{l})$ also showed significant, but lower amounts of copper after incubation of the CU-SURMOF 2 sample for $2 \mathrm{~h}$.

Additional file 2: Figure S2. SEM of attached bacteria after bacterial attachment. SEM measurements were performed to determine how localized the degradation of the CU-SURMOF 2 took place. Figure S2 a and $b$ shows SEM images of partially removed bacteria on CU-SURMOF 2 (20 layers) after gentle washing of the surface prior to drying. The original attachment position of the bacterium on the CU-SURMOF 2 can easily be seen as dark spot on the surface. Obviously the surface is only changed at the original position of attachment. This impression is supported by tilted SEM images after fracturing the samples (Figure S2c). The SURMOF next to the bacterium seems unaffected.

Additional file 3: Figure S3. Height determination of CU-SUMOF 2 after bacterial attachment. To further support the localized degradation of the Cu-SUMOF 2, we used AFM measurements. Figure $\mathrm{S3}$ shows the AFM image of CU-SURMOF $2(\approx 160 \mathrm{~nm})(\mathrm{A})$ and its height profile (B) from which its thickness was determined. Figure S3b shows that the thickness was $\approx 160 \mathrm{~nm}$ after bacterial incubation, the typical thickness of a CuSURMOF 2 consisting of 20 layers. In agreement with the tilted SEM images in Additional file 2: Figure S2C, it can be seen that the $\mathrm{Cu}$ SURMOF 2 film in the vicinity of the bacteria is preserved after the incubation with C. marina for $2 \mathrm{~h}$.

Additional file 4: Figure S4. Bacterial morphology after adhesion on CU-SURMOF 2. Figure S4 shows AFM images of C. marina on a CuSURMOF 2 (A) and on an HDT SAM (B) as control as well as the height profile $(C)$ indicated by the blue dotted and red line in $(A)$ and $(B)$. The flatter and rougher nature of the bacteria incubated on the CU-SURMOF 2 substrate is clearly visible in the height profiles.

\section{Abbreviations}

MOF: Metal-organic framework; SURMOF: Surface anchored metal-organic framework; PCP: Porous coordination polymer.

\section{Competing interests}

The authors declare no competing financial interests.

\section{Authors' contributions}

All authors analysed and discussed the data and contributed to writing the paper. All authors read and approved the final manuscript.

\section{Authors' information}

Authors Maria Pilar Arpa-Sancet and Maximilian Hanke shared first authorship.

\section{Acknowledgments}

We acknowledge the Office of Naval Research (Grant number N00014-08-11116) and the Helmholtz program Biolnterfaces for support of this work. M. Hanke acknowledges support by the Sander foundation (D10051281). We thank F. Friedrich and L. Xiao for support in acquisition of the SEM images, G. Albert for preparation of the gold coated glass slides, and P. Weidler for support in XRD measurements and discussions of the diffraction data.

\section{Author details}

${ }^{1}$ Institute of Functional Interfaces (IFG), Karlsruhe Institute of Technology, PO Box 3640, 76021 Karlsruhe, Germany. ${ }^{2}$ Applied Physical Chemistry, University Heidelberg, 69120 Heidelberg, Germany. ${ }^{3}$ Department of Medicine $\checkmark$, Heidelberg University, Heidelberg, Germany. ${ }^{4}$ Analytical

Chemistry-Biointerfaces, Ruhr-University Bochum, 44780 Bochum, Germany. 
Received: 17 September 2013 Accepted: 16 October 2013

Published: 6 November 2013

\section{References}

1. Thomas K, Raymond K, Chadwick J, Waldock M (1999) The effects of shortterm changes in environmental parameters on the release of biocides from antifouling coatings: cuprous oxide and tributyltin. Appl Organomet Chem 13:453

2. Brooks S, Waldock M (2009) In: Hellio C, Yebra D (ed) Advances in marine antifouling coatings and technology. Woodhead Publishing Limited, Cambridge, p 492

3. Callow JA, Callow ME (2011) Trends in the development of environmentally friendly fouling-resistant marine coatings. Nat Commun 2:244

4. Townsin RL (2003) The ship hull fouling penalty. Biofouling 19:9-15

5. Yebra DM, Kiil S, Dam-Johansen K (2004) Antifouling technology-past, present and future steps towards efficient and environmentally friendly antifouling coatings. Prog Org Coat 50:75-104

6. Swain GW (1999) Redefining antifouling coatings. Paint Coat Eur 4:18

7. An J, Geib SJ, Rosi NL (2009) Cation-triggered drug release from a porous zinc-adeninate metal-organic framework. J Am Chem Soc 131:8376

8. Horcajada P, Serre C, Maurin G, Ramsahye NA, Balas F, Vallet-Regi M, Sebban M, Taulelle F, Ferey G (2008) Flexible porous metal-organic frameworks for a controlled drug delivery. J Am Chem Soc 130:6774-6780

9. Arslan HK, Shekhah O, Wohlgemuth J, Franzreb M, Fischer RA, Woell C (2011) High-throughput fabrication of uniform and homogenous MOF coatings. Adv Funct Mater 21:4228-4231

10. Cobet AB, Wirsen C, Jones J, Jones GE (1970) The effect of Nickel on a marine bacterium Arthrobacter-Marinus new species. J Gen Microbiol 62:159-169

11. Arpa-Sancet MP, Christophis C, Rosenhahn A (2012) Microfluidic assay to quantify the adhesion of marine bacteria. Biointerphases 7:1-9

12. Mayer C, Moritz R, Kirschner C, Borchard W, Maibaum R, Wingender J, Flemming HC (1999) The role of intermolecular interactions: studies on model systems for bacterial biofilms. Int J Biol Macromol 26:3-16

13. Berney M, Hammes F, Bosshard F, Weilenmann H-U, Egli T (2007) Assessment and interpretation of bacterial viability by using the LIVE/DEAD BacLight kit in combination with flow cytometry. Appl Environ Microbiol 73:3283-3290

14. Boulos L, Prévost M, Barbeau B, Coallier J, Desjardins R (1999) LIVE/DEAD ${ }^{\circledR}$ BacLight $^{\mathrm{TM}}$ : application of a new rapid staining method for direct enumeration of viable and total bacteria in drinking water. J Microbiol Methods 37:77-86

15. Christophis C, Grunze M, Rosenhahn A (2010) Quantification of the adhesion strength of fibroblast cells on ethylene glycol terminated selfassembled monolayers by a microfluidic shear force assay. Phys Chem Chem Phys 12:4498-4504

16. Deen WM (1998) Analysis of Transport Phenomena

17. Young EWK, Wheeler AR, Simmons CA (2007) Matrix-dependent adhesion of vascular and valvular endothelial cells in microfluidic channels. Lab Chip 7:1759-1766

18. Nagarkar S, Williams GA (1997) Comparative techniques to quantify cyanobacteria dominated epilithic biofilms on tropical rocky shores. Mar Ecol Prog Ser 154:281-291

19. Nishino T, Ikemoto E, Kogure K (2004) Application of atomic force microscopy to observation of marine bacteria. J Oceanogr 60:219-225

20. Hanke M, Arslan HK, Bauer S, Zybaylo O, Christophis C, Gliemann H, Rosenhahn A, Woell C (2012) The biocompatibility of metal-organic framework coatings: an investigation on the stability of SURMOFs with regard to water and selected cell culture media. Langmuir 28:6877

21. Ista LK, Fan H, Baca O, Lopez GP (1996) Attachment of bacteria to model solid surfaces: oligo(ethylene glycol) surfaces inhibit bacterial attachment. FEMS Microbiol Lett 142:59-63

22. Ista LK, Mendez S, Lopez GP (2010) Attachment and detachment of bacteria on surfaces with tunable and switchable wettability. Biofouling 26:111-118

23. Shea C, Lovelace LJ, Smithsomerville HE (1995) Delaya Marina as a model organism for studies of bacterial-colonization and biofilm formation. J Ind Microbiol 15:290

24. Baumann L, Bowditch RD, Baumann P (1983) Description of Deleya gen nov. created to accommodate the marine species Alcaligenes aestus, A. pacificus, A. cupidus, A. venustus, and Pseudomonas marina. Int J Syst Bacteriol 33:793
25. Bauer S, Arpa-Sancet MP, Finlay JA, Callow ME, Callow JA, Rosenhahn A (2013) Adhesion of marine fouling organisms on hydrophilic and amphiphilic polysaccharides. Langmuir

26. Liu J, Lukose B, Shekhah O, Arslan HK, Weidler P, Gliemann H, Braese S, Grosjean S, Godt A, Feng X, Muellen K, Magdau I-B, Heine T, Woell C (2012) A novel series of isoreticular metal organic frameworks: realizing metastable structures by liquid phase epitaxy. Sci Rep 2

27. Arslan HK, Shekhah O, Wieland DCF, Paulus M, Sternemann C, Schroer MA, Tiemeyer S, Tolan M, Fischer RA, Wöll C (2011) Intercalation in layered metal-organic frameworks: reversible inclusion of an extended $\pi$-system. J Am Chem Soc 133:8158-8161

28. Trevors JT, Cotter CM (1990) Copper toxicity and uptake in microorganisms. $J$ Ind Microbiol 6:77-84

\section{doi:10.1186/1559-4106-8-29}

Cite this article as: Arpa Sancet et al:: Surface anchored metal-organic frameworks as stimulus responsive antifouling coatings. Biointerphases 2013 8:29.

\section{Submit your manuscript to a SpringerOpen ${ }^{\odot}$ journal and benefit from:}

- Convenient online submission

Rigorous peer review

- Immediate publication on acceptance

- Open access: articles freely available online

- High visibility within the field

- Retaining the copyright to your article

Submit your next manuscript at $>$ springeropen.com 